\title{
Trayectorias demográficas de Baja California y California, 1900-2000. Contrastes y paralelismos
} David Piñera Ramírez*, Ramiro Jaimes Martínez**, Pedro Espinoza Meléndez ${ }^{* * *}$

\section{Resumen}

El objetivo de este documento es analizar los procesos de la migración en dos entidades vecinas, California y Baja California, señalando sus características, la procedencia de los flujos migratorios y el tipo de relaciones laborales generadas a partir de este fenómeno. Por ello, con la migración como eje temático y siguiendo las pautas de la historia comparativa, se constata que tanto en California como en Baja California los flujos migratorios han desempeñado un papel fundamental. El enfoque comparativo lleva también a la búsqueda de similitudes y diferencias en etapas y coyunturas clave, como el impacto de la Ley Seca, la Gran Depresión y las dos guerras mundiales, o bien fenómenos específicos como la llegada del ferrocarril. El hilo conductor es la migración con sus dos aspectos fundamentales ya mencionados: la procedencia de las corrientes migratorias y las relaciones laborales que éstas han generado en las dos Californias.

Palabras clave: migración, historia comparativa, Baja California, California.

\section{Abstract}

The purpose is to analyze migration processes that have occurred in two neighboring states, pointing out the characteristics acquired in each of them, especially regarding their origin and type of labor relations they have produced. Therefore, the migration as the thematic axis and following the guidelines of comparative history, it is shown that both in California and in Baja California, migration flows have played a fundamental role. The comparative approach also leads to the search for similarities and differences represented in different moments, such as the impact of "Prohibition", the Great Depression and two World Wars, or specific phenomena as the arrival of the railroad. But above all, the common thread is migration with its two key issues mentioned above, the origin of migration flows and labor relations that they have generated in the two Californias.

Keywords: migration, comparative history, Baja California, California.

* Investigador del Instituto de Investigaciones Históricas, Universidad Autónoma de Baja California. Correo electrónico: davidpinera@uabc.edu.mx

** Investigador del Instituto de Investigaciones Históricas, Universidad Autónoma de Baja California. Correo electrónico: rjaimesm@yahoo.com

**** Estudiante de la maestría en Historia del Instituto de Investigaciones Históricas, Universidad Autónoma de Baja California. Correo electrónico: pe_dro87@hotmail.com 


\section{Introducción}

Cuando iniciamos nuestro estudio nos planteamos estas preguntas: ¿Cómo ha incidido la migración en los procesos históricos de Baja California y California?, y ¿ha tenido la migración características particulares en cada una de estas regiones, especialmente respecto de su procedencia y del tipo de relaciones laborales generadas? De estas interrogantes se deriva el eje temático del presente artículo: la migración y el propósito de analizar de manera comparativa su incidencia en cada una de las dos entidades aludidas, así como los lugares de origen de los flujos migratorios y las relaciones laborales generadas en virtud de ellos.

Hasta donde sabemos, y no obstante la vecindad entre Baja California y California, no hay estudios históricos que las aborden en forma comparativa, los que podrían redundar en ejercicios que permitan un mayor conocimiento de ambas entidades.

Sin embargo, autores como John H. Elliott han señalado la utilidad de encontrar diferencias y semejanzas en fenómenos pertinentemente seleccionados para confrontarlos (Elliott, 1999). En nuestro caso, la pertinencia se pone de manifiesto en el hecho de que hay identidad de tiempo y espacio, ya que durante el siglo $\mathrm{xx}$-en que se analizan las trayectorias demográficas-, Baja California y California tuvieron -y actualmente aún las tienen- las mismas dimensiones espaciales. Esto es, son los mismos espacios, analizados en el mismo marco temporal: 1900-2000.

Por su parte, Daniel Ziblatt, en Structuring the State. The Formation of Italy and Germany and the Puzzle of Federalism, se pregunta cómo se forman los Estados nacionales y qué determina si ello conduce a la elección de una u otra forma de gobierno. Su lectura pone de manifiesto la importancia de efectuar el enfoque comparativo que ello implica, con un criterio temático bien establecido, lo que en el caso que nos ocupa nos llevó a definir como eje a la migración, enfocándola en la procedencia de las corrientes migratorias y en las relaciones laborales por ellas generadas. ${ }^{1}$ En ese sentido, pudimos advertir que el factor migratorio, que fue una constante en Baja

\footnotetext{
${ }^{1}$ Aparte de la obra de Ziblatt, hay que mencionar también como trabajos comparativos importantes Slavery in the Americas: A Comparative Study of Virigina and Cuba, de Herbert S. Klein (1967), y Las revoluciones de independencia en México y en los Estados Unidos, de Richard Morris, Josefina Zoraida Vázquez y Elías Trabulce (1976).
} 
California y California a lo largo del periodo de estudio, en el fondo ha dado resultados dispares en ambas regiones, lo que se refleja en los contrastantes volúmenes de población total que éstas tienen en la actualidad, así como en su procedencia y el tipo de relaciones laborales que presentan.

Asimismo, tenemos que una vertiente metodológica de la historia comparativa tiende a encontrar similitudes entre las unidades sujetas a estudio. A ello ha hecho referencia Fernand Braudel (1993), y Elliott ha agregado que para que tales similitudes sean relevantes, es necesario no sólo yuxtaponer, sino confrontar a fondo las unidades de comparación (Elliott, 1999).

Por otra parte, Charles C. Regin ha puesto especial énfasis en la importancia de la búsqueda de contrastes, de diferencias, en lo que él llama la "investigación comparativa en torno a la diversidad" (Ragin, 2007). Así pues, tan necesario como buscar similitudes, es establecer divergencias que muestren lo propio de cada una de las entidades sujetas a comparación. Todo ello, repetimos, teniendo en nuestro caso a la migración como idea rectora.

Si bien se trata de dos entidades que forman parte de dos Estados-nación distintos, con políticas económicas y demográficas diferentes, esto no debe llevarnos a presuponer que California y Baja California son cultural y socialmente incomparables, o que lo han sido a lo largo de la historia. Como se verá, son dispares pero adyacentes y con una intensa interrelación que data desde antes del siglo xx. Es decir, Baja California y California tienen procesos y problemas compartidos que reflejan este gran intercambio de personas, bienes e ideas, que precisamente se complican por sus disparidades. Así, antes de asentar de manera tajante sus distancias, es necesario analizar desde una perspectiva histórica sus trayectorias. Para esto, el trabajo aborda las grandes tendencias poblacionales a lo largo del siglo xx, esperando que sirva como punto de partida para posteriores investigaciones que exploren con más detalle las coincidencias y las diferencias.

\section{El escenario natural}

Baja California y California comparten algunas características geográficas. La planicie costera del sur de California continúa en la costa noroeste de la península de Baja California, de tal manera que, por encima de la fron- 
tera internacional, hay una serie de rasgos ecológicos comunes que dan a la región binacional un ambiente mediterráneo (Omernik, 1986). Por otra parte, las condiciones desérticas del valle de Mexicali se continúan en el otro lado de la línea, en el Valle Imperial, y siguen más arriba en el desierto Mojave y en el Valle de la Muerte. La gran diferencia está en el dilatado y fértil Valle Central, que en el norte riegan los ríos Sacramento y San Joaquín, creando condiciones propicias para la agricultura. A eso debemos agregar la existencia de minerales y petróleo, lo que en conjunto explica algunos aspectos clave de la consistente y dinámica economía californiana. En cambio, sólo 10\% del territorio de Baja California es susceptible de aprovechamiento agrícola o ganadero, y respecto de los escasos recursos minerales, cuando se han explotado, ha sido en forma pasajera (INEGI, 1997).

\section{Antecedentes}

Para comprender mejor el periodo histórico de nuestro análisis, que va de 1900 a 2000, es pertinente considerar algunos fenómenos fundamentales que le antecedieron.

A lo largo del siglo xvin se dio un proceso de colonización de la península de Baja California mediante misiones jesuitas, primero, y franciscanas y dominicas, después. Serían 27 misiones que se establecieron partiendo del sur, hasta llegar a donde la península entronca con el macizo continental (Martínez, 2003). Ese proceso de expansión de la cultura hispano-católica continuó en lo que fue la Nueva o Alta California, denominada así para distinguirla de la Antigua o Baja California. Los franciscanos prosiguieron la expansión hacia el norte y en 1769 fundaron la misión de San Diego de Alcalá, primera de una serie de 21 misiones californianas (Herrera, 2007). Mediante ellas se sentaron las bases del desarrollo subsecuente de la región.

En términos comparativos, las misiones de la península, por lo desértico del suelo, generalmente fueron pequeñas y pobres, mientras que en las de la Alta California se cultivaba trigo, vid y olivo, con bastante buenos resultados, además de tener una significativa actividad ganadera (Hogan, 1991).

A raíz de la guerra de Independencia, en las siete misiones existentes en la parte norte de la península, en la superficie que hoy correspondería al actual estado de Baja California, había sólo alrededor de 600 indígenas 
misionados y 130 entre misioneros, soldados y rancheros. ${ }^{2}$ En cambio en la Alta California las misiones daban cabida a más de 18 mil indígenas y tanto en ellas como en los pueblos existentes había cerca de 3500 "gentes de razón”, esto es, españoles, criollos o mestizos (Bancroft, 1885).

La considerable cifra de 82597 habitantes que registró California en el censo de 1850, y que sería la primera migración fuerte que recibió, refleja la "fiebre del oro" desatada ahí en 1848, así como el hecho de que la entidad empezó a ser parte de la Unión Americana, consecuencia del Tratado de Guadalupe-Hidalgo suscrito en ese año por México y Estados Unidos (Vázquez y Meyer, 1982).

En el sensible incremento de 379994 habitantes en 1860 a 560247 en 1870, influyeron las intensivas labores agrícolas que se desarrollarían en los valles de Sonoma y San Joaquín, mientras que las corrientes migratorias que trajeron del este las vías del ferrocarril elevaron la población a 864694 para el año 1880 (Rawls y Bean, 1998).

Por su parte, como se aprecia en el cuadro 1, Baja California continuaba bastante despoblada, y en 1861 registraba sólo 3881 habitantes. Ese panorama empezó a modificarse en virtud de que la expansión económica que experimentaba Estados Unidos, del este al oeste, rebasó la línea fronteriza. Esto trajo una serie de inversiones estadounidenses que contribuyeron en el desarrollo de la región, e incluso propiciaron, a finales del siglo xix y principios del xx, el surgimiento de las poblaciones de Ensenada, Tijuana y Mexicali, que con sus variantes atraerían hacia ellas flujos migratorios. ${ }^{3}$

\section{Contrastes}

En estas características demográficas de las dos Californias podemos ver una serie de situaciones contrastantes que nos muestran una relación desigual tejida por ambas regiones a través del tiempo.

Lo primero que salta a la vista es la disparidad poblacional con la que iniciaron el siglo xx. De acuerdo con los datos censales de 1900, Baja Ca-

\footnotetext{
${ }^{2}$ Así lo menciona José María Echeandía, gobernador de las Californias, en su informe de 1829. Archivo General de la Nación, Ramo Gobernación, vol. 92, exp. 15, 1829.2. Copia en el archivo documental del Instituto de Investigaciones Históricas de la UABC. ${ }^{3}$ Al respecto puede consultarse la obra Los orígenes de las poblaciones de Baja California. Factores locales, nacionales y externos, de David Piñera (2006).
} 
Cuadro 1.

Población de Baja California y California en el siglo XIX

\begin{tabular}{|c|c|c|l|}
\hline Año & Baja California & California & \multicolumn{1}{|c|}{ Fuentes } \\
\hline 1836 & 4085 & & Martínez, 2002 \\
\hline 1850 & & 92597 & US Census Bureau \\
\hline 1855 & 2878 & & Magaña, 2004 \\
\hline 1856 & 4281 & & Trejo, 1994 \\
\hline & 4274 & & Magaña, 2004 \\
\hline 1860 & & 379994 & US Census Bureau \\
\hline 1861 & 3881 & & Trejo, 1994 \\
\hline 1870 & & 560247 & US Census Bureau \\
\hline 1880 & & 864694 & US Census Bureau \\
\hline 1887 & 7039 & & Lemoine, 1959 \\
\hline 1890 & & 1213398 & US Census Bureau \\
\hline 1900 & 7583 & 1485053 & INEGI, US Census Bureau \\
\hline
\end{tabular}

lifornia tenía apenas 7583 habitantes, mientras que en California vivía casi un millón y medio de personas. Como hemos señalado, la expansión económica de la Unión Americana en la segunda mitad del siglo xix había poblado a California (a partir de su anexión) a un ritmo pocas veces visto; mientras que en el caso de Baja California, la ausencia de vías de comunicación contribuyó a mantenerla escasamente poblada (gráficas 1 y 2).

En términos de densidad poblacional, California contaba con un promedio de 3.5 habitantes por $\mathrm{km}^{2}$, mientras que en Baja California los datos apuntan 0.1 habitantes por $\mathrm{km}^{2}$. En otras palabras, en el caso de esta última, se trataba de un territorio tradicionalmente despoblado, colindando con uno en pleno crecimiento económico y demográfico. Esto puede ayudarnos a entender por qué durante la primera mitad del siglo xx el Estado mexicano tuvo una constante preocupación en "poblar y mexicanizar" el Territorio Norte de Baja California, al punto de implementar diversas políticas de población orientadas a alentar la migración durante los gobiernos posrevolucionarios. ${ }^{4}$

${ }^{4}$ Especialmente destaca la política desplegada en el régimen del presidente Lázaro Cárdenas, que atrajo personas del interior del país mediante el reparto de tierras 


\section{Gráfica 1. Población total de México y Estados Unidos, 1900-2000}

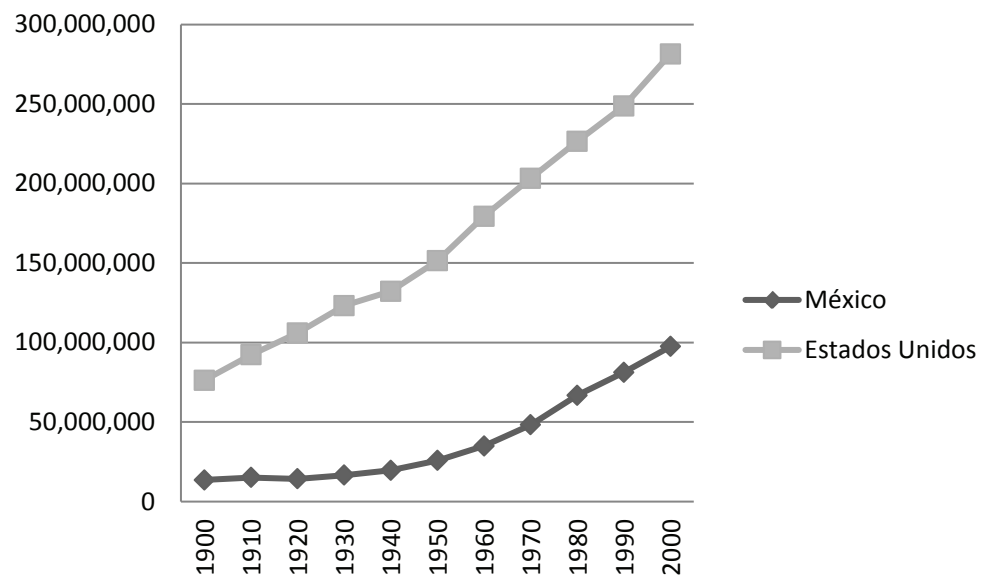

Fuentes: INEGI y US Census Bureau.

Gráfica 2. Población total de Baja California y California, 1900-2000

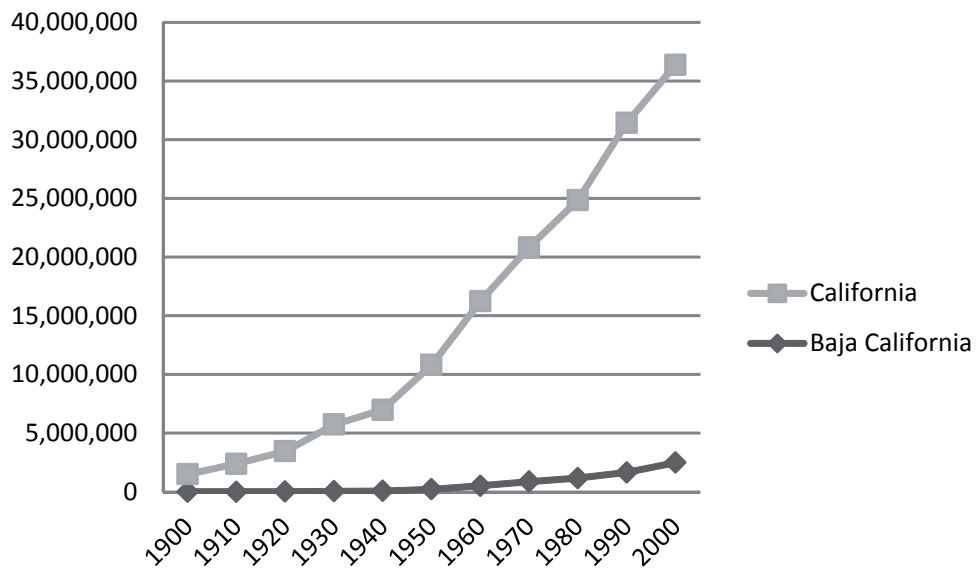

Fuentes: INEGI y US Census Bureau. 
Cabe señalar también que Baja California ocupó, hasta 1921, el lugar 31 de 32 entidades mexicanas en cuanto a su población, mientras que California ascendió de la posición 21 en 1900 a la 12 en 1910 y a la número 8 en 1920. En esos mismos años Baja California representaba entre $0.06 \%$ y $0.16 \%$ de la población nacional, mientras que en California se concentraba entre 2 y $3 \%$ del total de los habitantes de Estados Unidos.

Un aspecto a destacar es el hecho de que debido a la falta de comunicación con el resto del país y su escasa integración a la economía mexicana, la mayor parte del desarrollo económico y del crecimiento demográfico bajacaliforniano en la primera mitad del siglo xx se explica a partir de su relación con California (Samaniego, 2006).

Hacia las décadas de 1920 y 1930, la población de Baja California comenzó a aumentar de manera importante. Un hecho significativo fue la promulgación en Estados Unidos de la llamada Ley Seca, que prohibió la producción, la venta y el consumo de bebidas alcohólicas, a lo que se agregaría también la prohibición de los juegos de azar. Estas medidas motivaron que del lado mexicano se desarrollara una serie de actividades encaminadas a ofrecer a los estadounidenses lo que les negaba el prohibicionismo en su país. El fenómeno, con sus variantes, se dio a lo largo de la franja fronteriza mexicana, pero tuvo manifestaciones de mayor envergadura en la frontera de Baja California, dada su vecindad con el corredor San Diego-Los Ángeles-San Francisco, California, de notables dimensiones demográficas y económicas.

El caso más emblemático fue el complejo turístico de Agua Caliente, en Tijuana, que incluía casino, hotel, hipódromo, baños de aguas termales, pista de aterrizaje, etcétera. Este complejo fue construido mediante elevadas inversiones de estadounidenses, en subrepticia asociación con el entonces gobernador de la entidad, General Abelardo L. Rodríguez. A partir de su inauguración en 1928, Agua Caliente generó dinámicas interrelaciones económicas de diversa índole, como apuestas -frecuentemente cuantiosas-, servicios de hotelería, restaurantes, transportes, bares y todo lo que rodea a este tipo de actividades. Las nuevas fuentes de trabajo ocasionaron algunas disputas entre empleados estadounidenses y mexicanos, por lo que éstos se vieron en la necesidad de crear los que vendrían a ser

que inició en 1937, del latifundio de la Colorado River Land Company, en el valle de Mexicali (Cruz, 2007). 
los primeros sindicatos en la entidad, de meseros, cantineros, choferes y similares. Ello, entre otras cosas, atrajo nuevos migrantes a la localidad (Vanderwood, 2010).

Así, las tasas de crecimiento de Baja California se incrementaron por encima de las de California y de la media nacional, tanto de México como de Estados Unidos. Aunque, por otra parte, los números absolutos nos muestran el enorme contraste señalado anteriormente: 23500 habitantes en Baja California, frente a 3.4 millones en California en 1920, y 48 mil y 5.6 millones, respectivamente, una década más tarde. Además, a partir de 1930 la densidad demográfica de California superaba la media nacional de Estados Unidos (cuadro 2).

Algunos aspectos importantes del contexto histórico de las primeras décadas en California, vinculados con el crecimiento económico y el desarrollo de las relaciones laborales desde el siglo pasado, fueron la apertura agrícola del Valle Imperial (1902), la creación de la base naval de San Diego (1907), el establecimiento de la industria cinematográfica en Hollywood (1912), y la terminación de la Ruta 66, carretera que comunica a Los Ángeles con Chicago (1926) (Brinkley, 2003).

Sin embargo, en 1929 inició en Estados Unidos una crisis económica que se mantuvo por lo menos una década, situación que además de impactar en el desarrollo de California, trajo consigo repatriaciones de mexicanos residentes en Estados Unidos (Alanís, 2007). En la década de 1930 la tasa de crecimiento de ambas Californias se redujo de manera notable, aunque disminuyó más en California ya que la disminución del número de migrantes a Baja California se contrarrestó con los numerosos repatriados que llegaron a ella en estos años. ${ }^{5}$

Las décadas de 1940 y 1950 fueron de especial importancia para las dos entidades. Los procesos económicos desencadenados a partir de la Segunda Guerra Mundial tuvieron sus efectos en la realidad social y demográfica de ambas regiones. En el caso de California, la industria bélica cobró un auge inusitado, trayendo consigo no solamente un aumento en la tasa de crecimiento respecto de la década anterior, sino también un

5 La llamada Gran Depresión, iniciada en 1929 en Estados Unidos, provocó un grave desempleo que se tradujo en la expulsión de numerosos trabajadores mexicanos de la Unión Americana, y un número considerable de ellos llegó a Baja California, algunos con la esperanza de regresar a Estados Unidos y otros con la intención de radicarse aquí. 


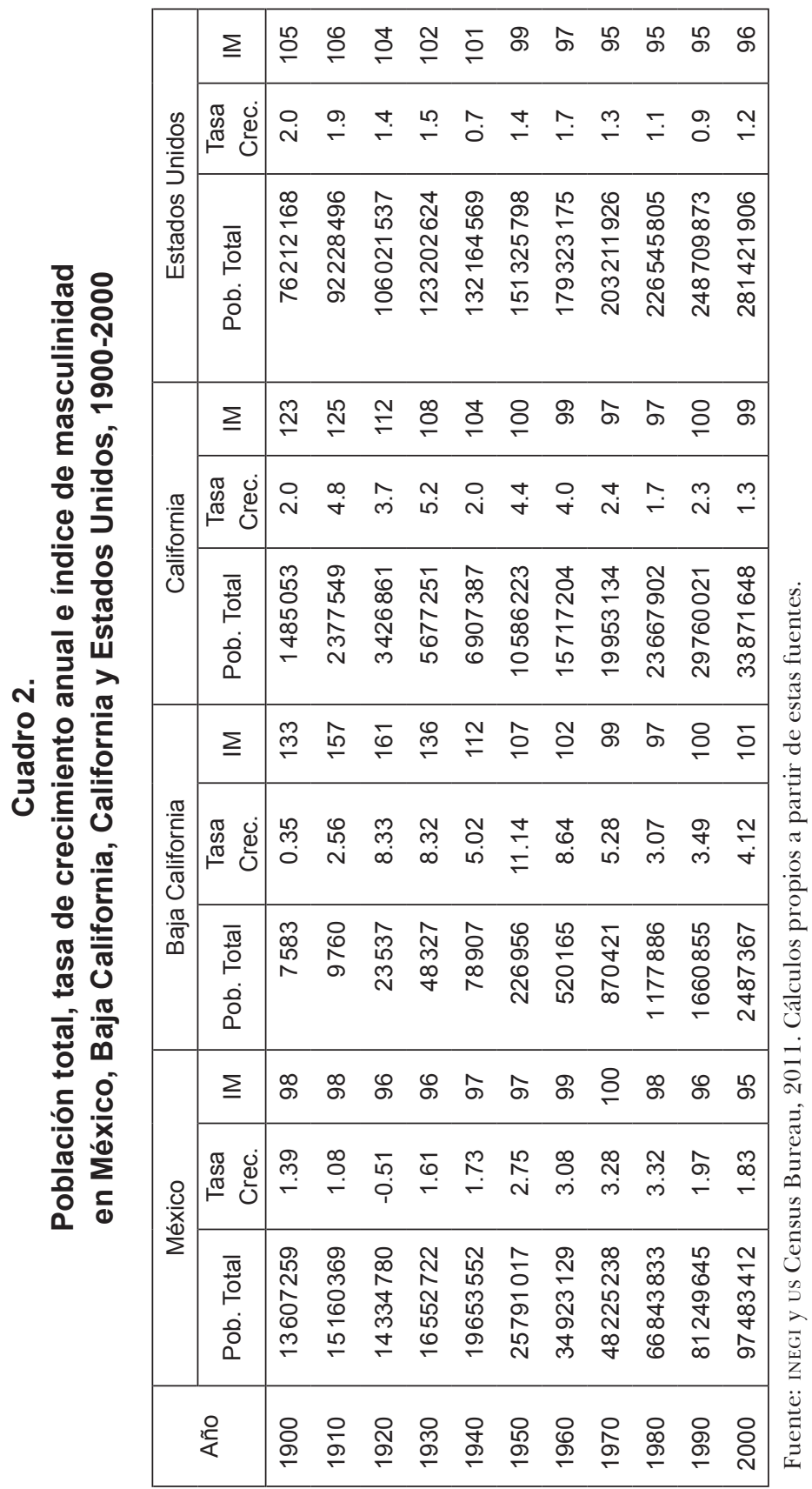


desarrollo económico sin precedentes, el cual impactó a Baja California de distintas maneras (Canales, 1995). Por un lado, la firma del programa Bracero dio facilidades a un gran número de mexicanos para cruzar a trabajar a Estados Unidos en labores agrícolas, pues la población estadounidense dedicada a estas actividades había sido reclutada para pelear en la guerra (Rawls y Bean, 1998).

Por otro lado, se dio un notable aumento de la actividad turística en Tijuana. Soldados y marinos de las bases de San Diego, así como trabajadores de las plantas industriales, se convirtieron en clientes asiduos de esta ciudad, pues no se limitaban a consumir sólo en los centros de "vicio", sino también en los de alimentos, ropa, medicinas y demás servicios (Hall, 1993). Mientras tanto, en el contexto agrícola de la entidad se dio un auge económico importante, ya que la mayor parte de la demanda del algodón cultivado en el valle de Mexicali se generó, en buena medida, a partir de las guerras mundiales (Martínez, 1993).

Para 1950, con más de 10 millones de habitantes, California era el segundo estado más poblado de la Unión Americana y concentraba $7 \%$ de la población estadounidense, mientras que Baja California tenía cerca de 227 mil habitantes, ocupando el lugar 27 dentro de las entidades mexicanas, que representaba menos del $1 \%$ de la población nacional. Por otra parte, el crecimiento experimentado por Baja California a mediados del siglo pasado le valió para que en 1952 dejara de ser un territorio federal y se convirtiera en un estado de la federación (González y Grijalva, 1998; Taylor, 2002).

Después de la Segunda Guerra Mundial, el auge económico de California, y su reflejo en Baja California, se mantuvo por algunos años. Sin embargo, la segunda mitad del siglo xx trajo una serie de cambios que en gran medida dieron forma a las actuales Californias. Se gestaron varios movimientos sociales importantes y la presencia mexicana se hizo cada vez más fuerte en California. Prueba de ello es el llamado Movimiento Chicano, en el que un considerable número de mexicano-americanos se organizó para reclamar sus derechos, como lo hicieron otras minorías, entre ellas las de los afroamericanos, asiáticos e indígenas nativos (Rawls y Bean, 1998). También vemos que en el censo de 1970, California figuró ya como el estado con mayor población de toda la Unión Americana, pues alcanzó casi 20 millones de habitantes que representaban cerca de 10\% de la población total del país. 
La aparición de nuevas tecnologías modificó el panorama industrial y económico de la región. Las fibras sintéticas reemplazaron al algodón, lo que influyó de manera negativa en el Valle imperial y en su vecino, el valle de Mexicali, que se habían dedicado a ese cultivo desde principios del siglo xx. Asimismo, la finalización del programa Bracero dejó a miles de mexicanos sin trabajo, situación que llevó al gobierno mexicano a iniciar el Programa de Industrialización Fronterizo. La concentración industrial en ambas Californias ha sido un fenómeno relevante desde la década de 1970, tanto en el desarrollo tecnológico del Silicon Valley en California, como en las maquiladoras bajacalifornianas.

Durante la segunda mitad del siglo xx, el significado de la migración de origen mexicano cambió de forma notable. En el caso de California y Estados Unidos, lo que antes había sido alentado por proyectos como el programa Bracero, finalizado en 1964, ahora comenzaba a restringirse, situación que se agudizó de manera progresiva hasta alcanzar niveles alarmantes, como lo prueba la implementación del Operativo Guardián a partir de $1994 .{ }^{6}$ Respecto de Baja California y México, a diferencia de las políticas de población implementadas varias décadas atrás para poblar esta entidad, en la década de 1960 la migración se convirtió en un problema social y económico, pues las autoridades tuvieron serias dificultades, para satisfacer las necesidades de vivienda, especialmente, sobre todo por la creciente población que llegaba a asentarse en la entidad (Piñera y Carrillo, 2010).

Hacia finales del siglo xx, los principales contrastes entre Baja California y California no fueron muy diferentes de los que ya hemos mencionado, si bien el contexto social, económico e incluso político ha cambiado. Pese a que la entidad estadounidense es casi seis veces mayor que la mexicana en cuanto a extensión territorial, su densidad de población es notablemente mayor, ubicándose por encima de la media nacional de Estados Unidos (cuadro 3).

En el año 2000, con sus más de 33 millones de habitantes, California concentraba más de $12 \%$ de la población estadounidense y seguía siendo el

\footnotetext{
${ }^{6}$ El gobierno de Estados Unidos puso en marcha ese operativo entre la frontera de California y Baja California argumentando que Tijuana reportaba la gran mayoría de los cruces ilegales, por lo que se emprendió la construcción de 630 millas de muro y se aumentó el número de los elementos de la Patrulla Fronteriza.
} 


\section{Cuadro 3.}

Población total, ranking y porcentaje de la población con respecto de su país, Baja California y California, 1900-2000

\begin{tabular}{|r|c|c|c|c|c|c|}
\hline \multirow{2}{*}{ Año } & \multicolumn{2}{|c|}{ Baja California } & \multicolumn{3}{|c|}{ California } \\
\cline { 2 - 7 } & Población total & $\#$ & $\%$ & Población total & $\#$ & $\%$ \\
\hline 1900 & 7583 & 31 & 0.06 & 1485053 & 21 & 1.95 \\
1910 & 9760 & 31 & 0.06 & 2377549 & 12 & 2.58 \\
1920 & 23537 & 31 & 0.16 & 3426861 & 8 & 3.23 \\
1930 & 48327 & 30 & 0.29 & 5677251 & 6 & 4.61 \\
1940 & 78907 & 28 & 0.40 & 6907387 & 5 & 5.23 \\
1950 & 226956 & 27 & 0.88 & 10586223 & 2 & 7.00 \\
1960 & 520165 & 22 & 1.49 & 15717204 & 2 & 8.76 \\
1970 & 870421 & 21 & 1.80 & 19953134 & 1 & 9.82 \\
1980 & 1177886 & 20 & 1.76 & 23667902 & 1 & 10.45 \\
1990 & 1660855 & 18 & 2.04 & 29760021 & 1 & 11.97 \\
2000 & 2487367 & 17 & 2.55 & 33871648 & 1 & 12.04 \\
\hline
\end{tabular}

Fuente: INEGI y us Census Bureau. Cálculos propios a partir de estas fuentes.

estado más poblado de la Unión Americana. Por su parte, Baja California contaba con cerca de 2.5 millones de habitantes -según datos censales del mismo año- y se colocaba en la posición 17 de 31 entidades, representando 2.5\% del número de habitantes de la República Mexicana (cuadro 4).

De esta manera, al finalizar el siglo xx había más mexicanos viviendo en California que en Baja California, y alrededor de $28 \%$ de la población residente en California había nacido en otro país, mientras que en Baja California, apena $2 \%$ de sus 2.5 millones nació en el extranjero. Este aspecto también nos habla de las marcadas diferencias demográficas entre ambos estados.

\section{Paralelismos}

Una vez revisados los contrastes entre California y Baja California, es pertinente señalar también las similitudes y los paralelismos entre estas dos 


\section{Cuadro 4.}

Población total y densidad demográfica de México, Baja California, California y Estados Unidos, 1900-2000

\begin{tabular}{|r|r|r|r|r|r|r|r|r|}
\hline \multirow{2}{*}{ Año } & \multicolumn{2}{|c|}{ México } & \multicolumn{2}{c|}{ Baja California } & \multicolumn{2}{c|}{ California } & \multicolumn{2}{c|}{ Estados Unidos } \\
\cline { 2 - 8 } & Pob. total & Densidad & Pob. total & Densidad & Pob. total & Densidad & Pob. total & Densidad \\
\hline 1900 & 13607259 & 6.9 & 7583 & 0.1 & 1485053 & 3.5 & 76212168 & 7.8 \\
1910 & 15160369 & 7.7 & 9760 & 0.1 & 2377549 & 5.6 & 92228496 & 9.4 \\
1920 & 14334780 & 7.3 & 23537 & 0.3 & 3426861 & 8.1 & 106021537 & 10.8 \\
1930 & 16552722 & 8.4 & 48327 & 0.7 & 5677251 & 13.4 & 123202624 & 12.5 \\
1940 & 19653552 & 10.0 & 78907 & 1.1 & 6907387 & 16.3 & 132164569 & 13.4 \\
1950 & 25791017 & 13.1 & 226956 & 3.2 & 10586223 & 25.0 & 151325798 & 15.4 \\
1960 & 34923129 & 17.8 & 520165 & 7.3 & 15717204 & 37.1 & 179323175 & 18.2 \\
1970 & 48225238 & 24.5 & 870421 & 12.2 & 19953134 & 47.1 & 203211926 & 20.7 \\
1980 & 66843833 & 34.0 & 1177886 & 16.5 & 23667902 & 55.8 & 226545805 & 23.1 \\
1990 & 81249645 & 41.4 & 1660855 & 23.2 & 29760021 & 70.2 & 248709873 & 25.3 \\
2000 & 97483412 & 49.6 & 2487367 & 34.8 & 33871648 & 79.9 & 281421906 & 28.6 \\
\hline
\end{tabular}

Fuente: INEGI y us Census Bureau. Cálculos propios a partir de estas fuentes.

entidades. No se trata de procesos idénticos ni de la misma escala, sino de aspectos comunes que ambas regiones han vivido y que nos permiten entender su estrecha relación desde sus orígenes.

En 1848, año de la conformación de la nueva frontera, ambos estados eran territorios periféricos dentro de sus respectivos países. California se hizo parte de la Unión Americana, por lo que se integró a un nuevo sistema económico, político y social. Sus tasas de crecimiento más elevadas, reflejo del poblamiento de territorios desocupados, se dieron justo inmediatamente después de su anexión a Estados Unidos (1850-1860), situación a la que siguió un fuerte flujo migratorio motivado por la llegada del ferrocarril a la costa del Pacífico en el año de 1868 (Rawls y Bean, 1998), lo que facilitó la comunicación de la entidad con su nuevo país. Baja California, a pesar de las ambiciones despertadas en los diplomáticos estadounidenses que habían negociado el Tratado de Guadalupe-Hidalgo, continuó perteneciendo a México (Martínez, 2003), y en lo que correspon- 
de a un incremento de la población, lo viviría casi un siglo después. Como ya se mencionó, fue en la década de 1940 cuando, bajo la influencia de la Segunda Guerra Mundial, la entidad experimentó el crecimiento más explosivo de su historia, y fue también durante esta década cuando llegó el ferrocarril a ella (Samaniego, 2006).

Otro aspecto a destacar es el hecho de que ambas entidades han mantenido a lo largo del siglo xx tasas de crecimiento por encima de sus respectivas medias nacionales, lo que puede observarse a partir de la década de 1910. Esta característica se mantiene hasta nuestros días y es resultado de la migración hacia ambas entidades. Además, los comportamientos de estas tasas de crecimiento a lo largo de estos cien años muestran similitudes que hablan de que en ocasiones han sido los propios procesos los que han atraído a un importante número de pobladores hacia ambos lados de la frontera (gráficas 3 y 4 ).

Tanto California como Baja California tuvieron un crecimiento importante en las primeras décadas del siglo pasado, fenómeno que puede vincularse con los procesos de expansión y consolidación de ambos Estados nacionales, al igual que con los efectos económicos de la Primera Guerra Mundial. En el caso de Baja California, cabría anotar que en la década de 1910 tuvo una tasa de crecimiento de $8.33 \%$ anual, mientras que a nivel nacional se presentó un decremento en la población (tasa de $-0.51 \%$ ) debido a los efectos de la Revolución mexicana. En ese mismo periodo, California presentó una tasa de crecimiento poblacional de 3.7\%, frente a $1.9 \%$ en el resto de Estados Unidos.

De igual manera, la caída en las tasas de crecimiento entre 1930 y 1940 en ambas entidades se explica por los efectos sociales de la crisis económica iniciada en 1929 (Espinoza y Ham, 2011): de 8.3 a 5 en Baja California, de 5.2 a 2 en California, y de 1.5 a 0.7 en Estados Unidos. En este caso, el comportamiento demográfico de México fue distinto, pues hubo un ligero aumento en dicho indicador, de 1.6 a 1.7, que podría explicarse por las políticas implementadas por los gobiernos posrevolucionarios (Cruz, 2007).

Esta situación se invirtió en la siguiente década (1940), cuando la prosperidad en la industria bélica californiana durante la Segunda Guerra Mundial atrajo a un gran número de migrantes (Starr, 2005), lo que repercutió en Baja California. Para ésta, que contaba con poca población, ese crecimiento le significó las tasas más elevadas de su historia, mientras 
Gráfica 3. Tasas de crecimiento anual en México y Estados Unidos, 1900-2000

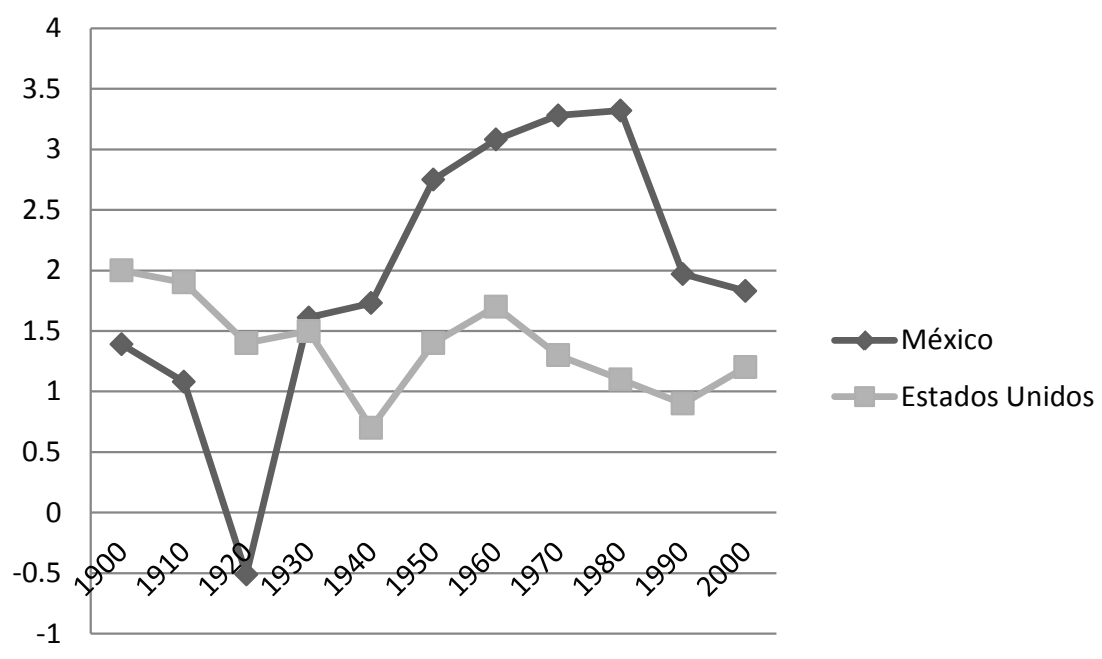

Fuentes: INEGI y US Census Bureau.

Gráfica 4. Tasas de crecimiento anual en Baja California, 1900-2000

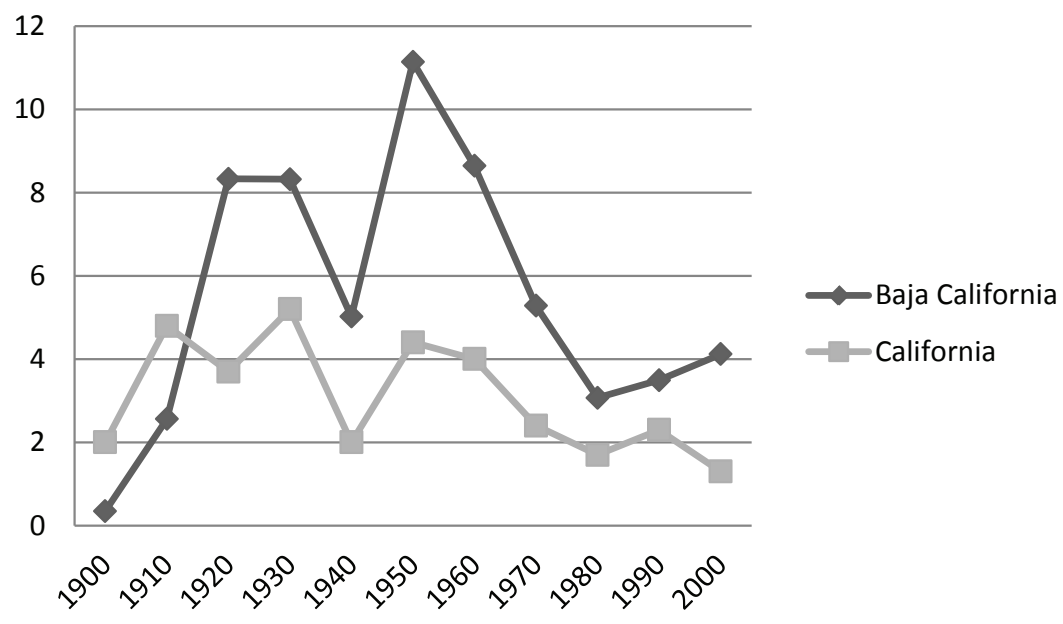

Fuentes: INEGI y US Census Bureau. 
que California, que ya contaba con casi siete millones de habitantes, nunca volvió a tener los índices de crecimiento registrados en 1930 o los de mediados del siglo xix.

Entre 1950 y 1980 las dos Californias presentaron una importante disminución en sus tasas de crecimiento, pues éstas cayeron de 11.4 para Baja California y 4.4 para California en 1950, a 3.07 y 1.7, respectivamente, en 1980.

En lo referente a México y Estados Unidos, ambos países han experimentado una disminución más o menos constante en sus tasas de crecimiento desde 1960 y hasta finales de siglo xx, aunque en el año 2000 se observó un ligero repunte en Estados Unidos.

Uno de los principales indicadores demográficos de la migración, que puede observarse tanto en California como en Baja California, es el predominio de población masculina a lo largo del siglo xx; en este sentido, hemos tomado el índice de $\operatorname{masculinidad}^{7}$ como referencia para comparar ambas entidades, mismo que, al igual que las tasas de crecimiento, es considerablemente mayor que el de sus respectivos países. En 1900, en México había 98 hombres por cada 100 mujeres y 105 en Estados Unidos; en ese mismo año, el índice de masculinidad en Baja California era de 133 y 123 en California. Los índices de masculinidad más altos registrados posteriormente a lo largo del siglo xx fueron de 125 para California en 1910, cuando en Estados Unidos era de 106; y 161 para Baja California en 1921, cuando en México era de 96.

A partir de estos años, los índices de masculinidad en general descendieron para ambas entidades, alcanzando sus niveles más bajos entre las décadas de 1970 y 1980, ya que, circunstancialmente, en este último año fue de 97 para ambas entidades -si bien en los dos censos posteriores tuvieron ligeros repuntes.

\section{Interacciones en las últimas décadas}

La tupida red de relaciones entre California y Baja California hacen necesario este apartado, para referirlas en sus rasgos fundamentales. Como ya apuntamos, la Segunda Guerra Mundial significó un considerable cre-

${ }^{7}$ El índice de masculinidad se refiere al número de hombres por cada cien mujeres dentro de una población. 
cimiento para California, en virtud, entre otros factores, del desarrollo tecnológico que alcanzó su industria de la defensa, impulsado por apoyos gubernamentales, escenario que continuaría en los años de la posguerra y de la Guerra Fría. Cabe destacar las sofisticadas tecnologías que ahí se implementaron y que requirieron la inmigración de personal altamente calificado. Asimismo, llegaron numerosos trabajadores agrícolas y obreros mexicanos en el marco del programa Bracero que estuviera vigente durante 22 años (1942-1964).

La incapacidad del gobierno mexicano para producir las fuentes de trabajo que demandaba el incremento demográfico del país, motivó que se resintiera la falta de trabajo para los braceros en California (Mendoza, 2009), por lo que el gobierno se vio en la necesidad de implementar el Programa de Industrialización Fronteriza (PIF), a partir de 1965, que dio origen a las plantas maquiladoras. Así, la industria maquiladora ha adquirido un papel fundamental en el desarrollo económico y demográfico de la región fronteriza, en especial a partir de las dos últimas décadas del siglo xx, toda vez que las plantas maquiladoras representaron el sector productivo más dinámico para liderar la economía (Turner, 2009).

Especial mención requiere el desarrollo logrado en Baja California, sobre todo en la producción de televisores, resultado del considerable número de empresas maquiladoras estadounidenses y asiáticas de alto nivel tecnológico establecidas en la entidad: el estado ostenta más de un tercio de las plantas maquiladoras del país y más de una quinta parte de los empleos y valor agregado maquilador generados en México. La concentración de plantas de origen asiático en la zona Tijuana-Mexicali convierte a Baja California en el centro productor de televisores más grande del mundo (Mungaray et al., 2011). Al respecto, conviene agregar que si bien un considerable número de estas plantas maquiladoras es de propiedad japonesa, coreana y china, la producción está dirigida al mercado estadounidense, incluido obviamente el de California.

En este sentido, las maquiladoras de la rama aeronáutica establecidas en Baja California producen para la industria aeroespacial civil o militar del vecino país. Ello corrobora lo señalado en cuanto a que la industria maquiladora en el lado mexicano y la de alta tecnología en el lado estadounidense han dado un carácter especial a la economía regional de la franja 
fronteriza (Vázquez, 2005). Ello explica la idea que se tiene de esta región como lugar de fuente de trabajo, lo que resulta atractivo para quienes se encuentran en el desempleo y tienen que migrar en busca de mejores oportunidades.

\section{La migración y su procedencia}

En cuanto a la procedencia de los migrantes que han arribado a las dos entidades objeto de estudio, las graficas 5 y 6 muestran la dinámica registrada en este sentido en la segunda mitad del siglo xx, esto es, entre los años 1950 y 2000. Las gráficas muestran los cambios registrados en cada uno de los censos decenales en cuanto a aspectos migratorios como: los nacidos en la propia entidad, los nacidos en otro estado del país respectivo, los nacidos en otro país. En términos generales, puede observarse el crecido número de personas que no nacieron en ninguna de estas dos entidades. Asimismo, se aprecia el considerable número de migrantes llegados a California de otros países, incluido en forma significativa México.

Las gráficas 7 y 8 y los cuadros 5 y 6 se refieren de manera específica al año 2000 y presentan de forma puntual la composición demográfica de las dos entidades en lo que corresponde a la procedencia de la población. Para el caso de Baja California, se advierte que en el año $200048 \%$ de la población era nativa de la entidad y alrededor de $41 \%$ era originaria de otros estados, destacando la presencia de Sinaloa (7\%), Jalisco (5\%), Sonora (4\%), Michoacán (4\%) y el Distrito Federal (3\%). Este dato nos habla de que no se trata sólo de un éxodo rural, sino también de una importante migración de ciudad a ciudad, incluso desde la que cuenta con mayor población. Otro dato relevante es que cerca de $2 \%$ de la población de Baja California es de origen extranjero, destacando los nacidos en Estados Unidos, muchos de los cuales son hijos de padres mexicanos radicados en Baja California.

En el caso de California, como puede observarse en el cuadro 6 y la gráfica 8, en el año $200050 \%$ de su población había nacido en el estado y alrededor de $22 \%$ provenía de otras entidades de la Unión Americana. De ese 22\%, 7\% es nacido en los estados del Medio Oeste, que destacan por ser mayormente rurales. Les siguen $6 \%$ nacido en los estados del sur, que comparten varias características socioeconómicas con los del Medio 


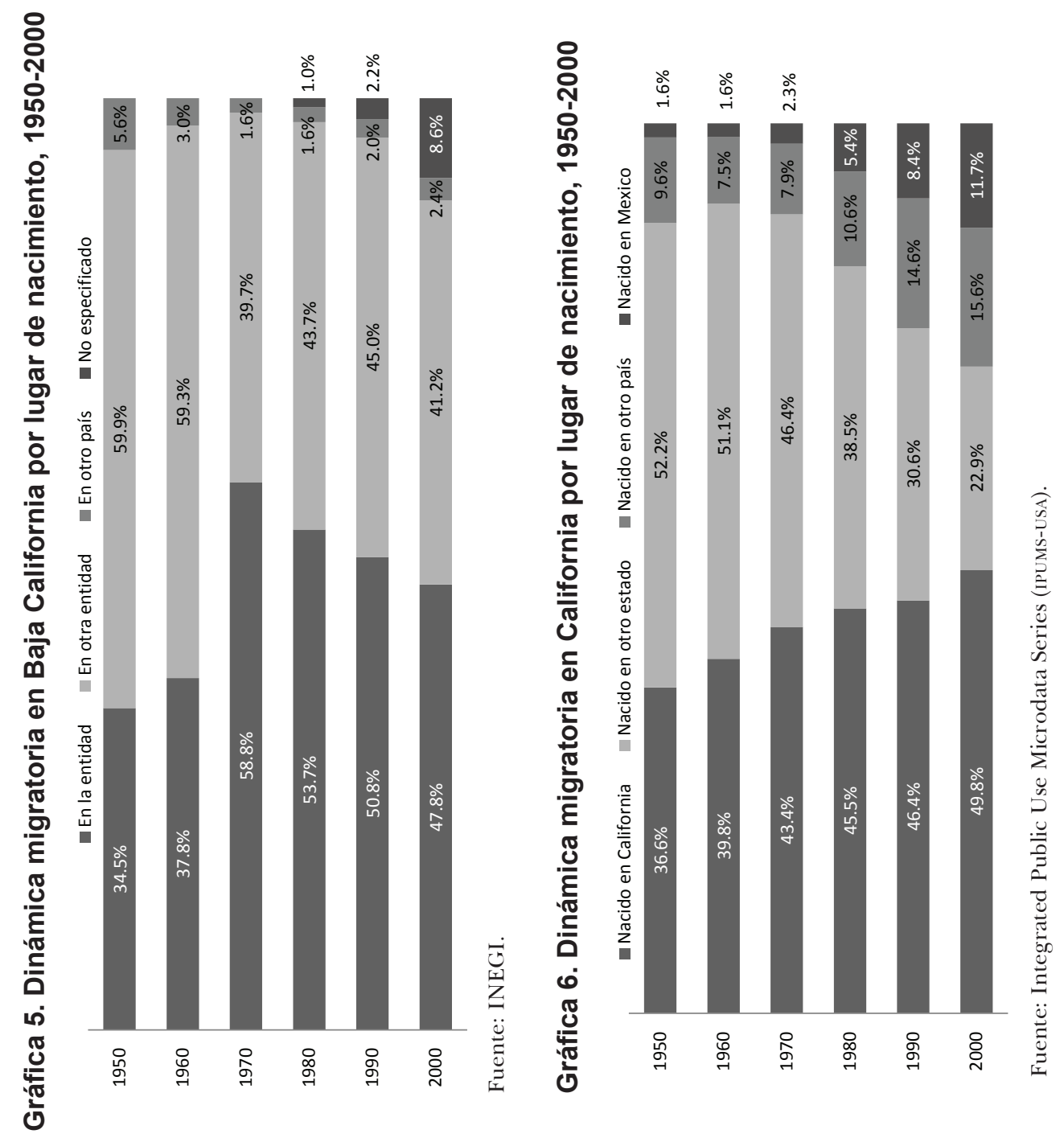


Gráfica 7. Orígenes de la población de Baja California, 2000

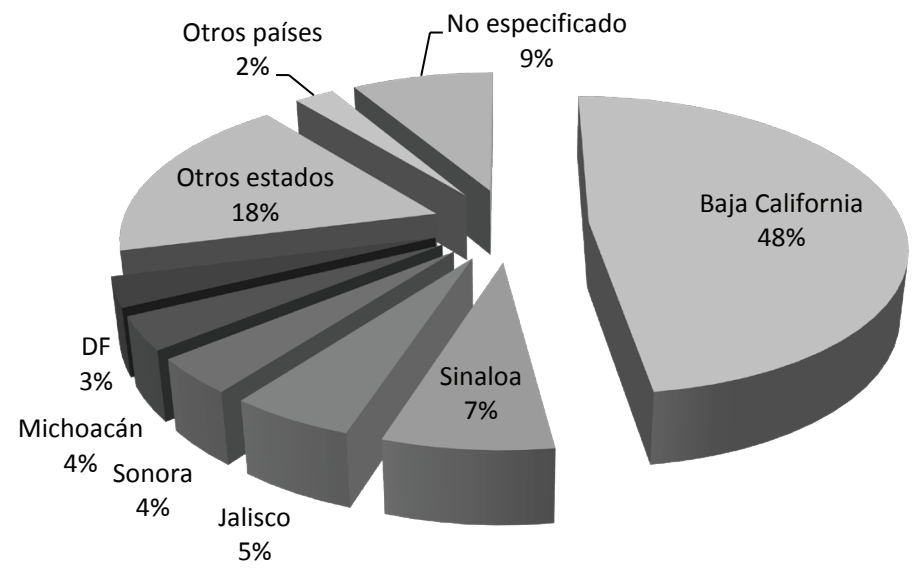

Fuente: INEGI 2011.

Gráfica 8. Orígenes de la población de California, 2000

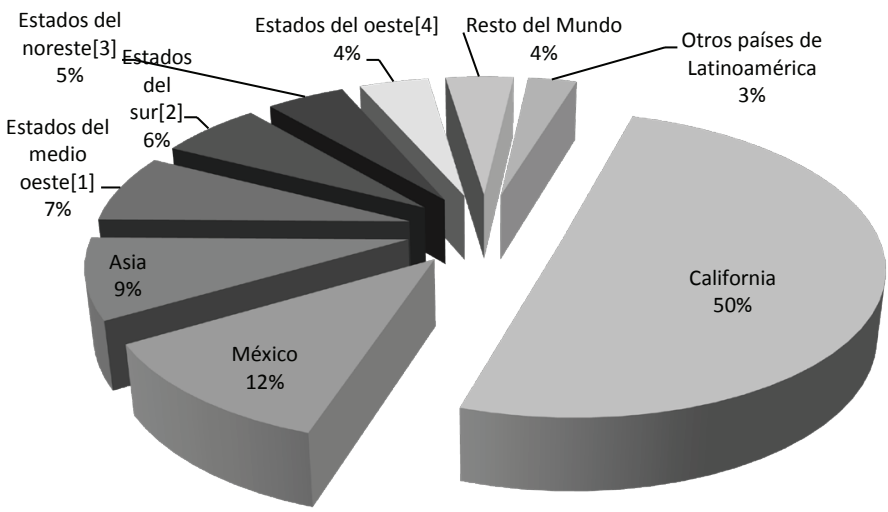

Fuente: US Census Bureau, 2011. 


\section{Cuadro 5.}

Orígenes de la población de Baja California, 2000

\begin{tabular}{|l|r|}
\hline Baja California & 1188787 \\
\hline Sinaloa & 180390 \\
\hline Jalisco & 132447 \\
\hline Sonora & 95509 \\
\hline Michoacán & 89083 \\
\hline DF & 79621 \\
\hline Otros estados & 448704 \\
\hline Otros países & 59716 \\
\hline No especificado & 213110 \\
\hline Total & 2487367 \\
\hline
\end{tabular}

Fuente: INEGI, 2009.

Cuadro 6.

Orígenes de la población de California, 2000

\begin{tabular}{|l|r|}
\hline California & 17019097 \\
\hline México & 3928701 \\
\hline Asia & 2918642 \\
\hline Diversas regiones de la Unión Americana: \\
\hline Estados del Medio Oeste ${ }^{1}$ & 2489648 \\
\hline Estados del sur $^{2}$ & 2087408 \\
\hline Estados del noreste $^{3}$ & 1612380 \\
\hline Estados del oeste $^{4}$ & 1425187 \\
\hline Resto del mundo $^{|l|}$ & 1392416 \\
\hline Otros países de América Latina & 998102 \\
\hline Total & 33871581 \\
\hline
\end{tabular}

Fuente: US Census Bureau 2009.

${ }^{1}$ De acuerdo con el us Census Bureau, los estados del Medio Oeste son: Dakota del Norte, Dakota del Sur, Illinois, Indiana, Iowa, Kansas, Michigan, Minnesota, Missouri, Nebraska, Ohio y Wisconsin.

${ }^{2}$ Los estados del sur son: Alabama, Arkansas, Carolina del Norte, Carolina del Sur, Delaware, Florida, Georgia, Kentucky, Louisiana, Maryland, Mississippi, Oklahoma, Tennessee, Virginia y Virginia del Oeste.

${ }^{3}$ Los estados del noreste son: Connecticut, Maine, Massachusetts, New Hampshire, Rhode Island, Vermont, Nueva Jersey, Nueva York y Pennsylvania.

${ }^{4}$ Los estados del oeste son: Alaska, Arizona, California, Colorado, Hawaii, Idaho, Montana, Nevada, Nuevo México, Oregón, Utah, Washington y Wyoming. 
Oeste. El 5\% era originario de los estados del noreste, y $4 \%$ de los estados del oeste, caracterizados por tener mayores concentraciones urbanas y un importante desarrollo industrial. México apareció como el país de origen de $12 \%$ de la población, notable mayoría del total de $15 \%$ originario de América Latina en general. Destaca también que $9 \%$ era de origen asiático $\mathrm{y}$, finalmente, $4 \%$ del resto del mundo.

Como puede advertirse, los datos corroboran ese significativo paralelismo entre California y Baja California, consistente en que cerca de la mitad de sus pobladores son nativos y el resto originarios de otros lugares. En Baja California predomina la migración interna y en California la internacional.

\section{Conclusiones}

Las preguntas formuladas en el inicio de nuestra investigación, respecto de cómo ha incidido la migración en los procesos históricos de Baja California y California, así como las particularidades que ha tenido en cada una de ellas, especialmente en lo relativo a su procedencia y al tipo de relaciones laborales que ha generado, han sido el eje temático que permitió adquirir una visión comparativa de la migración en ambas entidades. Independientemente de las diferencias de fondo que apuntamos al inicio del documento, y sobre las que volveremos al final de estas conclusiones, también ha sido esclarecedor el señalamiento de contrastes específicos y similitudes en coyunturas y etapas puntuales, que enriquecen la percepción sobre el fenómeno.

Recapitulando estos aspectos específicos, tenemos que los escenarios naturales de ambas entidades son distintos, toda vez que destacan las propicias condiciones de California para actividades agrícolas, ganaderas e industriales, frente a las limitaciones que al respecto presenta Baja California.

Ello explica sus diversos contrastes, entre los que destaca la marcada disparidad con que iniciaron el siglo xx: Baja California con sólo 7538 habitantes, mientras que su vecina contaba con casi millón y medio. Así, Baja California figuraba en el penúltimo lugar entre las entidades de la República Mexicana en cuanto a población, lo que motivó a que se diseñaran políticas para poblarla, especialmente durante el régimen de Lázaro Cárdenas. 
El auge que significó para California la Segunda Guerra Mundial, la llevó a ocupar en 1950 el segundo lugar del país en cuanto a población, y para 1970 alcanzó el primer lugar, que conserva hasta el presente. Por su parte, Baja California sólo ha logrado llegar al número 17.

Sin embargo, frente a estos contrastes encontramos también notorios paralelismos. A lo largo del siglo xx ambas entidades mantuvieron tasas de crecimiento por arriba de sus respectivas medias nacionales. Además, ambas entidades experimentaron una caída en sus tasas de crecimiento entre 1930 y 1940 a consecuencia de la crisis económica de 1929, y ambas crecieron al impulso de la segunda conflagración mundial.

Pero quizá la semejanza más notoria es la relativa al origen de la población. Los datos muestran que tanto en Baja California como en California cerca de la mitad de los habitantes es nativa y la otra mitad originaria de diversos lugares. Además, la distribución de los nacidos fuera presenta semejanzas. En el caso de Baja California los porcentajes de personas procedentes de Sinaloa, Jalisco, Sonora, Michoacán y el Distrito Federal tienen similitud con los porcentajes de California, provenientes de los estados del Medio Oeste, sur, norte y oeste de la Unión Americana.

Es decir, ambas entidades han sido asiento de corrientes migratorias procedentes de diversas latitudes y países, lo que da a su composición demográfica un sentido plurirregional que se acentúa, en el caso de California, con la presencia de personas originarias de diversos países asiáticos y latinoamericanos. Entre éstos destaca México, lo que se traduce en otro punto de afinidad con Baja California.

A manera de recapitulación, podemos señalar que hasta la segunda mitad del siglo xIx, esto es, cuando tanto California como Baja California pertenecían a México, ambas entidades estaban escasamente pobladas. Esa circunstancia varió para California en cuanto formó parte de la Unión Americana, pues al incorporarse a su sistema político y socioeconómico empezó a incrementarse su población mediante corrientes migratorias procedentes del este, que propiciaron un dinámico desarrollo económico en el que el ferrocarril desempeñó un papel fundamental. Ése fue el inicio de un notable crecimiento en diversos rubros, como el agrícola, comercial, portuario e industrial. Este último en particular se vería impulsado por los conflictos bélicos en que ha participado el país, especialmente la Segunda Guerra Mundial, que le benefició de manera significativa por los 
elevados apoyos gubernamentales recibidos para incrementar su industria de defensa, a fin de satisfacer las necesidades del estado de guerra. Todas estas circunstancias han dado por resultado que la California actual, con sus más de 33 millones de habitantes, sea la entidad más poblada de toda la Unión Americana y una de las economías más ricas no sólo del país sino del mundo entero. Hay que recordar, para los efectos de nuestro artículo, que tal fenómeno se ha dado en una sociedad en la que la migración, tanto la procedente de otros estados del país como la extranjera, ha tenido un papel fundamental.

Por otra parte, si tomamos el mismo punto de referencia del trazo de la frontera en 1848, encontramos que el poblamiento de Baja California ha sido lento. Por largo tiempo ha estado aislada del centro del país y desligada en muchos aspectos de su economía. Carente de vías de comunicación que la integraran, estuvo vinculada en forma dependiente a la economía de la vecina California, de tal manera que su bienestar dependió durante varias etapas del desarrollo californiano más que de las políticas económicas nacionales. Esto se evidenció en el impacto que tuvieron en ella los años de la Ley Seca en Estados Unidos, y si bien los esfuerzos del régimen cardenista aspiraron a integrar más estrechamente a la región con el resto del país, pronto los efectos de la Segunda Guerra Mundial volverían a ligarla a la economía californiana. El fin del programa Bracero y el impulso de las maquiladoras para suplirlo, reflejan la permanencia de una estrecha vinculación de Baja California con California. Desde otro ángulo, ya en el año 2000, los dos millones y medio de habitantes de nuestra entidad, frente a los más de 33 millones de su vecina, resultan muy escasos (gráficas 9 y 10), sobre todo si recordamos que ambas entidades, en 1848, estaban igualmente despobladas. La diferencia, habrá que reconocerlo, la marcaron las economías nacionales operantes en cada una de ellas. 


\section{Gráfica 9. Porcentaje de la población de México representada} por Baja California, 2000

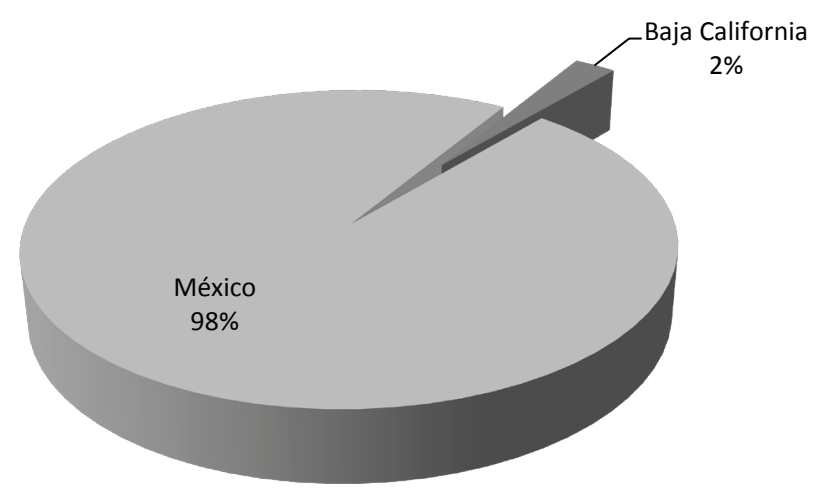

Fuente: INEGI.

Gráfica 10. Porcentaje de la población de Estados Unidos representada por California, 2000

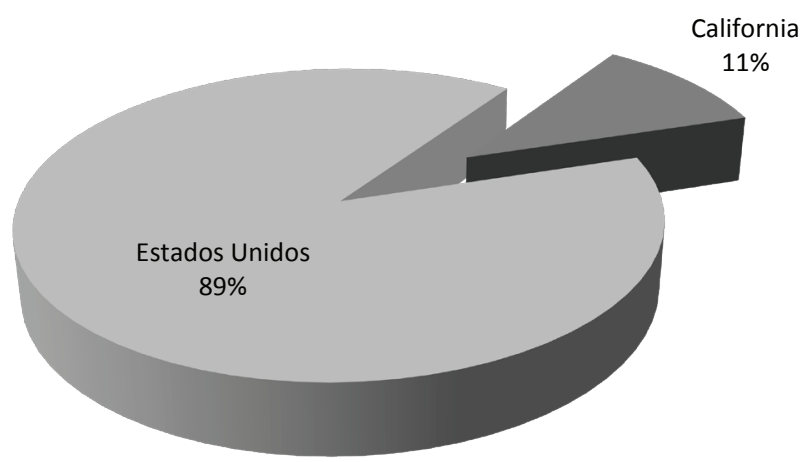

Fuente: US Census Bureau. 


\section{Bibliografía}

A. Hall, Kimberly (1993), "Women in Wartime: The San Diego Experience, 1941 1945”, The Journal of San Diego History, vol. 39, núm. 4, San Diego Historical Society.

Alanís, Fernando Saúl (2007), Que se queden allá. El gobierno de México y la repatriación de mexicanos en Estados Unidos (1934-1940), México, El Colef/Colsan.

Berenger, Valerié et al. (2009), Veinticinco años de investigación económica sobre la frontera norte de México, Tijuana, El Colegio de la Frontera Norte.

Bancroft, Hubert H. (1885), History of California II, 1801-1821, San Francisco, California, The History Company.

Braudel, Fernand (1993), La identidad de Francia. El espacio y la historia, España, Gedisa.

Brinkley, Alan (2003), Historia de los Estados Unidos. Un país en formación, México, McGraw-Hill.

Bustamante, Jorge A. (1997), Cruzar la Línea. La migración de México a los Estados Unidos, México, Fondo de Cultura Económica.

Canales, Alejandro (1995), "El poblamiento de Baja California, 1848-1950", Frontera Norte, vol. 7, núm.13, México, El Colef.

Corrales, Salvador et al. (2009), 25 años de integración económica en la frontera norte de México, Tijuana, El Colegio de la Frontera Norte.

Cruz, Norma del Carmen (2007), "El poblamiento de Baja California y la influencia de la política de población en el periodo cardenista”, Estudios Fronterizos, nueva época, vol. 8, núm. 16, julio-diciembre, pp. 91-122, Universidad Autónoma de Baja California.

Elliott, John H. (1999), "La historia comparativa”, Relaciones. Estudios de Historia y Sociedad, vol. XX, núm. 77, Zamora, El Colegio de Michoacán.

Espinoza, Pedro y Roberto Ham Chande (2011), "Un siglo de crecimiento demográfico en Baja California”, en David Piñera y Jorge Carrillo (coords.), Baja California a cien años de la Revolución mexicana, 1910-2010, México, Universidad Autónoma de Baja California, El Colegio de la Frontera Norte.

Fuentes, César y Sergio Peña (coords.) (2005), Planeación binacional y cooperación transfronteriza en la frontera México-Estados Unidos, Tijuana, El Colegio de la Frontera Norte.

González, Manuel y Aidé Grijalva (1998), Digesto constitucional mexicano: la Constitución Política de Baja California, México, Universidad Autónoma de Baja California.

Hall, A. Kimberly (1993), "Women in wartime: The San Diego Experience, 1941 - 1945”, The Journal of San Diego History, vol. 39, núm. 4 (San Diego Historical Society). 
Herrera, Pablo (2007), Fray Junípero Serra. Civilizador de las Californias, México, Universidad Autónoma de Baja California.

Hogan, Elizabeth L. (1991), The California Missions, Menlo Park, California, Sunset Publishing Corporation.

Inegi (1996), Estados Unidos Mexicanos. Cien años de censos de población, México.

— (1997), Síntesis geográfica de México, México.

- (2011), Censos y conteos de población y vivienda, 1900-2010. HTTP://WWW.INEGI. ORG.MX//EST/CONTENIDOS/PROYECTOS/CCPV/DEFAULT.ASPX?

Lemoine Villicaña, Ernesto (1959), "Evolución demográfica de la Baja California”, Historia Mexicana, núm. 2, octubre-diciembre, El Colegio de México.

Magaña, Mario Alberto (2004), "El poblamiento de Baja California durante el siglo xıx: reflexión desde la historia demográfica”, Estudios Fronterizos, vol. 5, núm. 10, México, Universidad Autónoma de Baja California.

Martínez, Jorge (1993), Mexicali, una historia, México, Universidad Autónoma de Baja California.

(2002), "Fundación de ranchos y colonización civil en la frontera, 18221848”, en Catalina Velázquez (coord.), Baja California. Un presente con historia, t. 1, Mexicali, Universidad Autónoma de Baja California.

Martínez, Pablo L. (2003), Historia de Baja California, México, Universidad Autónoma de Baja California.

Mendoza Cota, Jorge Eduardo (2009), "Regiones fronterizas frente a la migración: el caso de México y el Maghreb”, Ra Ximhai, vol. 5, núm. 1, pp. 49-66.

Mungaray, Alejandro, Antonio Escamilla, Natanael Ramírez y Gabriel Aguilar (2011), "Desarrollo económico y estructura de empleo en Baja California", en David Piñera y Jorge Carrillo (coords.), Baja California a cien años de la Revolución mexicana, 1910-2010, México, Universidad Autónoma de Baja California, El Colegio de la Frontera Norte.

Omernik, James M. (1986), Ecoregions of the United States, Washington, D.C., Environmental Protection Agency.

Osio, Antonio María (1996), The History of Alta California. A Memoir of Mexican California, Chicago, Illinois, The University of Wisconsin Press.

Piñera, David (2006), Los orígenes de las poblaciones de Baja California. Factores externos, nacionales y locales, México, Universidad Autónoma de Baja California.

Piñera, David y Jorge Carrillo (coords.) (2010), Baja California a cien años de la Revolución Mexicana. 1910-2010, Universidad Autónoma de Baja California / El Colegio de la Frontera Norte.

Ragin, Charles (2007), La construcción de la investigación social. Introducción a los métodos y su diversidad, Colombia, Universidad de los Andes.

Rawls, James y Walton Bean (1998), California. An Interpretative History, séptima edición, McGraw-Hill. 
Samaniego, Marco Antonio (2006), Breve historia de Baja California, México, Universidad Autónoma de Baja California.

Starr, Kevin (2005), California, A History, Nueva York, Modern Library.

Taylor, Lawrence (2002), “La creación del estado de Baja California, 1951-1955”, en Catalina Velázquez Morales (coord.), Baja California. Un presente con historia, t. II, México, IIH, UABC.

Trejo, Dení (1994), "La población de la California Peninsular en el siglo xix", en Dení Trejo y Marco Antonio Landavazo, Población y grupos de poder en la península de Baja California, La Paz, Universidad Autónoma de Baja California Sur.

Turner, E. H. y A. Díaz (2009), "Desarrollo e integración del norte de México y el sur de los EUA a partir del análisis de la evolución de las ciudades fronterizas”, Análisis Económico, XXIV, pp. 141-168.

us Census Bureau (2011), Census of Population and Housing, 1850-2010, en http:// www.census.gov/prod/www/abs/decennial/index.html

Vanderwood, Paul (2010), Satan's Playground: Mobsters and Movie Star at America's Greates Gaming Resort, Durham, N.C., Duke University Press.

Vázquez, Josefina Zoraida y Lorenzo Meyer (1982), México Frente a Estados Unidos: Un ensayo histórico, 1776-1980, Colegio de México.

Vázquez, M.T. (2005), Planificación bilateral México-Estados Unidos: instituciones, planificadores y comunidades (ciudadanos), en Centro de Investigaciones sobre América del Norte unAm. Nuevos actores en América del Norte. Seguridad, energía, economía y medio ambiente, México, Antal, Edit.

Ziblatt, Daniel (2006), Structuring the State. The Formation of Italy and Germany and the Puzzle of Federalism, Princeton, N.J., Princeton University Press, p. 220.

Zinn, Howard (2005), La otra historia de Estados Unidos, México, Siglo XXI.

Artículo recibido el 8 de diciembre de 2011

Segunda versión recibida el 4 de mayo de 2012

Artículo aprobado el 4 de junio de 2012 